\title{
Asthma, rhinitis, and dermatitis in workers exposed to reactive dyes
}

Ralph Nilsson, Rolf Nordlinder, Urban Wass, Birgitta Meding, Lars Belin

\begin{abstract}
A survey was conducted at 15 textile plants with dyehouses in western Sweden. Employees with a history of work related rhinitis, asthma, or skin symptoms were offered a clinical and immunological investigation including skin prick tests, skin patch tests, and radioallergosorbent tests (RASTs) to detect specific allergy to reactive dyes. Among the 1142 employees, 162 were exposed to reactive dyes and 10 of these $(6 \%)$ reported work related respiratory or nasal symptoms. An allergy to reactive dyes could be confirmed in five $(3 \%$, $95 \%$ confidence interval 1-7\%). All but one had been exposed to reactive dyes for one year or less before the onset of symptoms. Positive RASTs could be detected in four of the five patients. All of the RAST positive patients were positive to remazol black $B$, but six out of eight additional remazol dyes also elicited positive results. RAST and RAST inhibition showed a cross reactivity between some of the dyes. Seven persons with work related dermatitis and three with urticaria or Quincke oedema were found. In one patient contact dermatitis to a monoazo dye was shown, but no positive patch test reactions to reactive dyes. IgE-mediated allergy to reactive dyes seems to be an important cause of respiratory and nasal symptoms among dyehouse employees exposed to dust from reactive dyes.
\end{abstract}

(British Journal of Industrial Medicine 1993;50:65-70)

\footnotetext{
Department of Occupational Medicine, Sahlgrenska Hospital, St Sigfridsgatan 85, S-412 66 Göteborg, Sweden

R Nilsson, $R$ Nordlinder

The Asthma and Allergy Research Centre, Department of Medicine I, Sahlgrenska Hospital, S-413 45 Göteborg, Sweden

$\mathrm{U}$ Wass, L Belin

Section of Occupational Dermatology, Department of Dermatology, Sahlgrenska Hospital, S-413 45 Göteborg, and Department of Occupational Dermatology, National Institute of Occupational Health, S-171 84 Solna, Sweden

Birgitta Meding
}

Reactive dyes are widely used in the textile industry, owing to their ability to produce strong covalent bonds to textile fibres. Exposure to the dyes may be a potential health hazard, and several reports of asthma and rhinitis caused by such dyes have been published. ${ }^{1-10}$ Positive skin prick tests and positive results to the radioallergosorbent test (RAST) have suggested that airborne dye molecules may act as haptens and provoke the production of reactive dye specific immunoglobulin E (IgE) antibodies. ${ }^{14-14}$ Allergic contact dermatitis and urticaria from reactive dyes have also been reported. ${ }^{5}$

Most textile industries in Sweden are located in the western region, and this article reports the results of a survey of dyehouse employees in this region. The objective of the survey was to identify suspected cases of work related rhinitis, asthma, or dermatitis. These people were offered a medical examination including a skin prick test, RAST, and patch tests to elucidate the aetiology of the symptoms.

Because several of the workers seemed to be allergic to the same dye (remazol black B, colour index name: reactive black 5), we used this dye to develop an optimised RAST for reactive dyes. ${ }^{12}$ In the present paper we report the results of the survey, with clinical and immunological findings and the occurrence of cross reactivity between different dyes.

\section{Materials and methods}

STUDY GROUP

Fifteen textile plants with dyehouses in the western region of Sweden were included in the study. The plants were of varying size (25-200 workers) with annual consumption of reactive dyes in a range from 200 to $30000 \mathrm{~kg}$ (median $2000 \mathrm{~kg}$ ).

The plants were visited by a physician and an occupational hygienist from the Department of Occupational Medicine, Sahlgrenska hospital. Employees who had experienced work related symptoms from the skin or airways during the most recent five year period were identified through interviews with the company physicians and nurses, the management representatives, and the trade union occupational safety officers. We visited all the dying, weighing, and laboratory departments and interviewed all staff on duty that day. Symptomatic subjects not present at the day of the visit (for 
example, because of sick leave or working night shifts) were identified through interviews with their supervisors and occupational safety officers.

The total number of employees at the plants was 1142 , but most of them were not exposed directly to reactive dyes. There were 229 persons employed in the dyehouse and laboratory departments. Twenty five of these were dye storemen, mixers, and weighers who were exposed to dye powders for most of their working day (exposure group 1). Eighty seven were exposed to dye powders as part of their job as dyersfor instance, when mixing and dissolving dye powder in the dying bath (exposure group 2). Fifty employees were exposed to small quantities of dyes intermittently as supervisors or laboratory staff (exposure group 3). These job categories roughly correspond to groups 1-3 in the article by Docker and coworkers. ${ }^{6}$ Sixty seven employees in these departments and employees in other departments of the plants had little or no exposure to reactive dyes (exposure group 4).

\section{CLINICAL INVESTIGATIONS}

Employees with work related asthma or rhinitis were referred to The Asthma and Allergy Research Centre, Sahlgrenska hospital, where they were investigated by specialists in allergology and occupational medicine and by an occupational hygienist. The investigations included a history directed at the identification of upper and lower respiratory tract symptoms, and their relation to work, time of onset, and duration.

Spirometry and, in most cases, a metacholine challenge test were conducted. The metacholine test was done with stepwise inhalation of $0.1 \mathrm{mg}, 1.0 \mathrm{mg}$, and $10 \mathrm{mg}$ of nebulised metacholine in saline using an inhalator (PariBoy) followed by spirometry (Ohio) immediately and five minutes after the inhalation. The test was considered positive (the patient had a bronchial hyperreactivity (BHR)) if the fall in forced expiratory volume in one second $\left(\mathrm{FEV}_{1}\right)$ was greater than $25 \%$ after inhalation of $10 \mathrm{mg}$ metacholine (corresponding roughly to a $\mathrm{PD}_{20}$ of $8 \mathrm{mg}$ ).

Employees with a history of work related dermatitis were referred to the Section of Occupational Dermatology, Sahlgrenska hospital for patch testing.

\section{IMMUNOLOGICAL INVESTIGATIONS}

Nine suspected commercial reactive dye powders (listed in table 3 ), brought in by the patients, were used in standard prick tests, RASTs, and skin patch tests.

Prick tests were performed with common aeroallergens, reactive dyes diluted in saline-glycerol to a final concentration of $2 \mathrm{mg} / \mathrm{ml}$, and with a conjugate between remazol black $B$ and human serum albumin $(1.5 \mathrm{mg} / \mathrm{ml})$. Previous observations have shown that unconjugated remazol black $B$ could be used in skin prick tests and the reactive dyes were consequently used without any binding to a protein carrier. ${ }^{12}$ The remazol black $B$ conjugate was, however, used in the test to study any differences in performance between the conjugate and the unconjugated dye. Histamine hydrochloride $(10 \mathrm{mg} / \mathrm{ml})$ was the positive and saline-glycerol solution the negative control.

Patch testing was carried out with the standard series recommended by the Swedish Contact Dermatitis Group, a series of 12 organic textile dyes (azo and antraquinone) and the nine reactive dyes ( $1 \%$ in water) (see table 3 ). The test substances except for the reactive dyes were obtained from Chemotechnique Diagnostics AB, Sweden. Finn Chambers (Epitests Ltd Oy, Finland) and Scanpore tape (Norgeplaster, Norway) were used. The test patches were removed after 48 hours and assessment of the reactions was made 72 hours after application.

For the $R A S T s$, conjugates between reactive dyes and human serum albumin were prepared as previously described. ${ }^{12}$ Briefly, human serum albumin $(6 \mathrm{mg} / \mathrm{ml})$ was allowed to react with an equal volume of the dye $(1 \mathrm{mg} / \mathrm{ml})$ for one hour at $\mathrm{pH} 8.8$ and $20^{\circ} \mathrm{C}$. Minicon-B15 concentrators (Amicon Corp, Lexington, Mass.) were used for the removal of low molecular weight substances from the conjugates (an $0.1 \mathrm{~mol} / 1 \mathrm{NaHCO}_{3}$ buffer was used). When conjugates were used for RAST, 16 hours was allowed for the coupling to $\mathrm{CNBr}$ activated paper discs. A standard RAST procedure was used and the results were expressed as RAST classes according to the Phadebas RAST Reference System (Pharmacia Diagnostics, Uppsala, Sweden). The limit for a positive test (RAST class 1 ) corresponded to roughly $2 \%$ of the total activity added.

Non-specific binding to the discs was investigated with two different serum pools from persons with no known exposure to reactive dyes. The concentrations of total IgE in the pools were 35 and $2000 \mathrm{kU} / 1$. Total IgE was determined by the PRIST method (Pharmacia Diagnostics, Uppsala, Sweden). Only a low degree of non-specific binding to the discs was seen $(<0.7 \%$ of the total activity).

Whether any cross reactivity existed between different dyes was investigated by RAST and RAST inhibition. Conjugates prepared from the dyes giving positive RASTs were used in the RAST inhibition experiments in which $50 \mu \mathrm{l}$ of serum was preincubated overnight with $60 \mu \mathrm{g}$ of conjugate. In the first experiment, remazol black B conjugates were coupled to the RAST discs and serum was preincubated with various dye-human serum albumin conjugates. Combinations of sera and dyes that had produced at least a RAST class 2 were chosen for a second inhibition experiment, in which an opposite approach was adopted: Different dye conjugates were coupled to the discs and the remazol black B conjugate was used for inhibition. 
Table 1 Summary of background and exposure variables and clinical and immunologiral findings in the IS patients

\begin{tabular}{|c|c|c|c|c|c|c|c|c|c|c|c|c|c|c|c|c|}
\hline Patient & $A$ & $B$ & $C$ & $D$ & $E$ & $F$ & $G$ & $H$ & $I$ & $J$ & $K$ & $L$ & $M$ & $N$ & $O$ & Comment \\
\hline Age (y) & 35 & 31 & 24 & 57 & 42 & 33 & 19 & 48 & 57 & 29 & 44 & 46 & 46 & 20 & 33 & mean $37 \cdot 6$ \\
\hline & $\mathbf{M}$ & $\mathbf{M}$ & $\mathbf{M}$ & $\mathbf{M}$ & $\mathbf{M}$ & $\mathbf{M}$ & W & $\mathbf{M}$ & $\mathbf{M}$ & W & $\mathbf{M}$ & $\mathbf{M}$ & $\mathbf{M}$ & $\mathbf{M}$ & $\mathbf{M}$ & $13 \mathrm{M}, 2 \mathrm{~W}$ \\
\hline Smoker & No & Ex & Ex & Yes & No & Yes & No & Yes & No & & Ex & Yes & Ex & $\bar{\pi}$ & $\overline{-}$ & \\
\hline Occupation* & D & D & L & W & $\mathrm{L}$ & W & $\mathrm{O}$ & S & D & O & D & $\mathbf{W}$ & $\mathbf{W}$ & D & D & $4 \mathrm{~W}, 6 \mathrm{D}, 2 \mathrm{~L}, 1 \mathrm{~S}, 2 \mathrm{O}$ \\
\hline Exposure group $\star$ & 2 & 2 & & 1 & 3 & 1 & 4 & 3 & 2 & & 2 & 1 & 2 & & 2 & \\
\hline $\begin{array}{l}\text { Latency } \\
\text { Atopy. }\end{array}$ & $\operatorname{lm}$ & $6 \mathrm{~m}$ & & $1 \mathrm{y}$ & $10 y$ & & & $1-2$ & 27 & $1-2 m$ & $2-3 y$ & $10 \mathrm{y}$ & $7 y$ & $2-3 m$ & $1 \mathrm{y}$ & median $1 \mathrm{y}$ \\
\hline & + & - & - & - & - & + & \multicolumn{9}{|c|}{ Atopy: } & \\
\hline $\begin{array}{l}\text { Family } \\
\text { Own }\end{array}$ & - & + . & - & - & - & \pm & $\begin{array}{lll}+ \\
+\end{array}$ & $\stackrel{+}{t}$ & \pm & $\begin{array}{l}- \\
-\end{array}$ & + & $\bar{t}$ & - & - & + & $7 / 14$ \\
\hline \multicolumn{17}{|l|}{ Respiratory symptoms: } \\
\hline Rhinitis & + & + & + & + & + & + & - & + & - & + & - & - & - & - & - & $8 / 15$ \\
\hline Asthma & + & + & - & + & - & - & + & - & + & + & - & - & - & - & - & $6 / 15$ \\
\hline Cough & + & + & + & + & + & - & - & - & + & + & - & - & - & - & - & $7 / 15$ \\
\hline \multicolumn{17}{|l|}{ Skin symptoms: } \\
\hline Dermatitis & + & - & - & + & - & - & + & - & - & - & + & + & - & + & + & $7 / 15$ \\
\hline Urticaria/Quincke & - & + & - & - & - & - & - & - & - & + & - & - & + & - & - & $3 / 15$ \\
\hline \multicolumn{17}{|l|}{ Skin patch test: } \\
\hline Standard series & - & - & - & - & - & - & - & - & - & - & - & - & - & - & - & $0 / 7$ \\
\hline Organic dye series & - & - & - & - & - & - & - & - & - & - & - & - & - & + & - & $1 / 7$ \\
\hline Reactive dyes & $-\dagger$ & - & - & - & - & - & - & - & - & - & - & - & - & - & - & $0 / 8$ \\
\hline \multicolumn{17}{|l|}{ Skin prick test: } \\
\hline Standard allergen & - & - & - & $+\ddagger$ & + & + & + & - & + & - & - & - & + & - & - & $6 / 13$ \\
\hline Reactive dyes & + & + & + & $+\ddagger$ & + & - & - & - & - & - & - & - & - & - & - & $5 / 14$ \\
\hline Total IgE $(\mathbf{k U} / \mathbf{l})$ & 510 & 150 & 120 & 360 & 55 & 35 & 20 & 260 & 25 & 22 & 7 & 35 & - & - & - & median 45 \\
\hline RAST (reactive dyes) & + & + & + & + & - & - & - & - & - & - & - & - & - & - & - & $4 / 12$ \\
\hline BHR & + & - & - & + & - & - & - & - & - & + & - & - & - & - & - & $3 / 6$ \\
\hline $\mathrm{FEV}_{1}(\%$ predicted $)$ & 104 & 104 & 100 & 92 & 103 & 114 & 93 & 68 & 64 & 101 & 119 & 90 & 95 & - & - & mean $96 \%$ \\
\hline
\end{tabular}

*See table 2 for explanations; fonly tested with three different reactive dyes $(7,8,9$, see table 3$)$; funspecific reactions to all allergens; $M=$ man; $\mathrm{W}=$ woman.

\section{Results}

\section{CLINICAL FINDINGS}

Seventeen dyehouse employees with work related respiratory or skin symptoms were identified at the survey and were offered further investigation at the hospital. Two persons declined the offer. Tables 1, 2, and 3 summarise the clinical and immunological findings in the remaining 15 employees.

Ten reported symptoms from the upper and lower respiratory tract and 10 had skin symptoms. Rhinitis was the most common symptom (8/15) followed by dermatitis (7/15). Symptoms of asthma (6/15) and bronchitis (7/15) were also common. Rhinitis often preceded the development of asthma.

A pathological spirometry $\left(\mathrm{FEV}_{1}<80 \%\right.$ predicted) or metacholine challenge test $\left(\mathrm{PD}_{20}<8 \mathrm{mg}\right)$ was found in five patients. Two patients (B and $C$ ) were asked to register peak expiratory flow at least four times a day for three weeks but no work related pattern could be detected.

We found seven cases of work related contact dermatitis and three cases of urticaria or Quincke oedema. All except two were weighers or dyers.

Table 2 tabulates the prevalence of work related symptoms and allergies during the past five years in different job and exposure categories found in this investigation. Among the 1142 employees, 162 handled reactive dyes in powder form at the time of the onset of symptoms (exposure groups 1-3). Ten of these $(6 \%)$ were identified as having work related nasal or respiratory symptoms. Assuming a Poisson distribution, the $95 \%$ confidence interval (95\% CI) for the five year period prevalence was $3-11 \%$.

IMMUNOLOGICAL FINDINGS

No positive patch test reactions to the allergens in the

Table 2 Five year prevalence of symptoms and immunological findings in different exposure groups and occupations

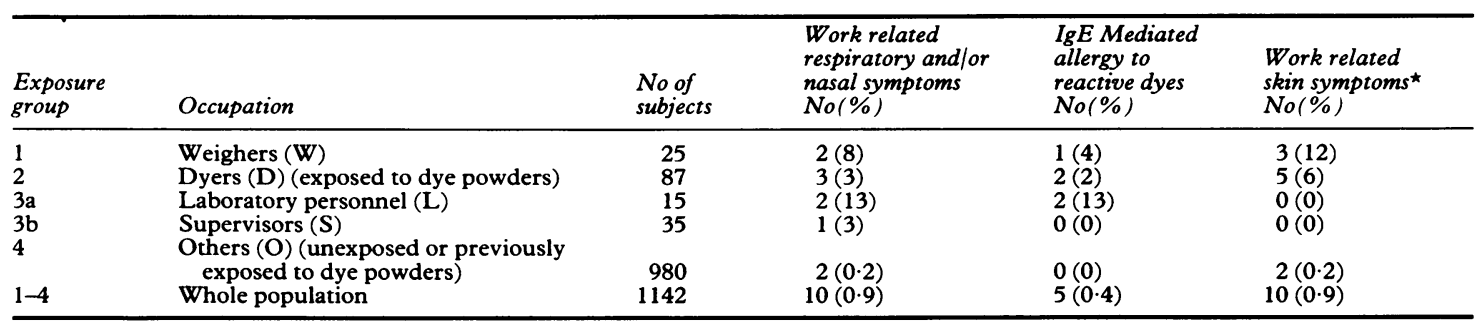

^No case of contact allergy to reactive dyes was found. 
Table 3 Reactive dyes used in skin prick tests and RASTs

\begin{tabular}{|c|c|c|c|c|c|c|}
\hline \multirow{2}{*}{\multicolumn{3}{|c|}{ Reactive dyes }} & \multicolumn{4}{|c|}{$R A S T$ classes } \\
\hline & & & \multicolumn{4}{|c|}{ Patients } \\
\hline No & Name of the reactive dye & Colour index name & $A$ & $B$ & $C$ & $D$ \\
\hline 1 & Remazol marine blue GG & Reactive blue 203 & 0 & 2 & 3 & 1 \\
\hline 2 & Remazol brilliant blue BB & Reactive blue 220 & 0 & 0 & 0 & 0 \\
\hline 3 & Remazol black B & Reactive black 5 & 2 & 2 & 3 & 2 \\
\hline 4 & Remazol brilliant green 6B & Reactive green 38 & 0 & 0 & 0 & 0 \\
\hline 5 & Remazol brilliant blue $\mathrm{R}$ spec. & Reactive blue 19 & 0 & 0 & 0 & 0 \\
\hline 6 & Remazol gold yellow RNL & Reactive yellow 107 & 0 & 2 & 2 & 1 \\
\hline 7 & Remazol brilliant orange FR & Reactive orange 82 & 0 & 1 & 0 & 2 \\
\hline 8 & Remazol brilliant yellow $4 \mathrm{GL}$ & Reactive yellow 160 & 0 & 1 & 0 & 2 \\
\hline 9 & Remazol black GF & Reactive black 5 & 1 & 2 & 3 & 1 \\
\hline
\end{tabular}

$\star$ Results of RAST expressed in RAST classes (class 0 indicates a negative test). Conjugates between reactive dyes and human serum albumin were coupled to the discs and serum from patients $A$ to $D$ were used.

standard series or to the reactive dyes were found. In one patient $(\mathrm{N})$ a positive reaction (erythema, infiltration) was noted for basic red $46(1 \%$ in petrolium jelly), which is a monoazo dye. One of the patients with urticaria (B) had positive prick tests to reactive dyes, and another $(M)$ to standard allergens.

Reactive dyes gave positive RASTs in four of the patients that had handled reactive dyes $(2 \%, 95 \% \mathrm{CI}$ $0 \cdot 7-6 \%$ ). All of them had worked as dyers, weighers, or in the laboratory and had been exposed to dye powders for one year or less before the onset of symptoms. In one case (E) a positive skin prick test with reactive dyes could not be confirmed with RAST. If this patient is included in the five year period, prevalence of IgE mediated allergy to reac- tive dyes among the exposed group in the dyehouse and laboratory departments could be estimated to $3 \%(95 \%$ CI $1-7 \%)$.

Irritant reactions to chemicals used in the dyehouse were suspected in the remaining five patients with respiratory or nasal symptoms. The latency time in this group ranged from one month to 27 years.

A history of atopy or a positive skin prick test for common allergens was found in most patients, although this seemed to be more common among patients with irritant reactions $(4 / 5)$ or skin symptoms $(8 / 10)$ than among patients with a specific allergy to reactive dyes $(2 / 5)$ (table 1$)$. Serum $\mathrm{IgE}$ concentrations were slightly raised $(>100 \mathrm{kU} / \mathrm{l})$ in five patients.

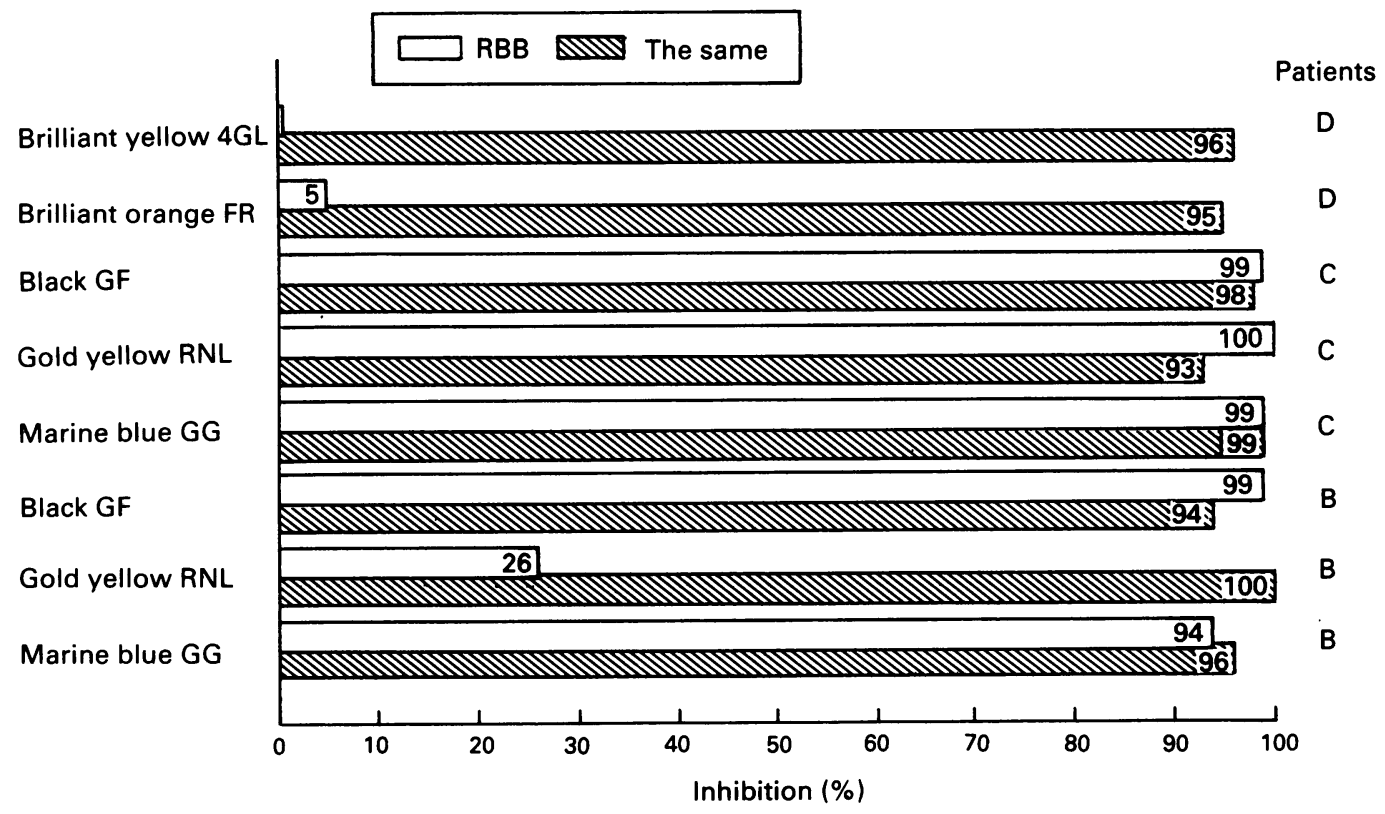

Results of RAST inhibition expressed as percentage inhibition. Discs with various dye-human serum albumin conjugates were used. Sera from patients $B, C$, and $D$ were preincubated with either the same conjugate as that bound to the disc (designated "the same" in the figure) or with a Remazol Black B-human serum albumin conjugate (" $R B B$ " in the figure). 
Six remazol dyes gave positive results in the RAST (table 3). The pattern of positive RASTs varied among the four positive patients, but they were all positive to remazol black $B$ and remazol black GF, both with the same colour index name (reactive black 5).

In the first RAST inhibition experiment, binding to remazol black $B$ discs could be inhibited by remazol black $B$ conjugates, but also with conjugates prepared from remazol marine blue GG and remazol black GF. In the second inhibition experiment, the dyes remazol marine blue $G G$ and remazol black $G F$ could be substituted for remazol black B without changing the outcome of the RAST inhibition significantly (fig).

The variation in the test procedures was found to be low, with a relative standard deviation (coefficient of variation) in the RAST and the RAST inhibition of $7 \%$ and $8 \%$ respectively. As an example, the true inibition percentage for a duplicate sample eliciting $50 \%$ inhibition could be estimated to be within the interval from $44 \%$ to $56 \%$ inhibition $(95 \% \mathrm{CI})$.

The performances of both unconjugated remazol black $B$ and a human serum albumin conjugate of the same dye in the skin prick test were studied. On a weight basis, at least twice the amount of conjugate was needed to produce the same reaction as that elicited by the unconjugated dye. As earlier studies had shown an average of seven dye haptens bound per molecule of human serum albumin in this conjugate, ${ }^{12}$ it was possible to recalculate the results with respect to the number of dye molecules available. The conjugated dye was found to be roughly twice as potent as the unconjugated dye. Results from the skin prick tests performed with unconjugated dyes showed a good correlation with the RAST results in the four RAST positive cases. One patient showed pronounced reactions in the skin prick test but no significant binding to the RAST discs could be noted.

\section{Discussion}

Work related respiratory and skin symptoms are not uncommon among dyehouse workers. In accordance with previous studies this study shows that reactive dyes are common causative agents for respiratory symptoms among dyehouse workers. After weighers, laboratory personnel showed the next highest prevalence of respiratory and nasal symptoms and IgE mediated allergy to reactive dyes (table 2). They handle dyes in smaller quantities (weighing and mixing) but probably more frequently than the dyers.

The prevalence of work related nasal and respiratory symptoms in the exposed group was lower in our study than in that by Docker and coworkers. ${ }^{6}$ They found higher percentages of positive RASTs in the exposed groups but lower proportions in the symptomatic groups. One reason for the difference in prevalence figures could be that they used a mixture of many dyes for RAST screening, whereas the patients in our study were encouraged to bring in dyes that they suspected to be the causative agents. Another explanation is that the handling of and exposure to reactive dyes may be different in the Swedish and English plants. In both studies atopy was common in the symptomatic groups.

Another difference between the two studies is that Docker and coworkers used questionnaires to identify cases with symptoms, whereas we interviewed all employees in the dyehouse and laboratory departments that were present at the day of the investigation (most employees). For identification of cases among the rest of the staff, we had to rely on interviews with supervisors, occupational safety officers, and company physicians and nurses. We think that we have identified the same number of cases in the dyehouse and laboratory departments as we would have done using a questionnaire, although the estimated prevalence of cases in other departments may have been underestimated.

The prevalence figures found in our investigation should be considered as minimum values as some cases could have remained undetected, although considerable efforts were made to identify them, especially in the dyehouse and laboratory departments. Persons with work related symptoms probably have an increased tendency to change occupations or stop working.

The prevalence figures for a specific allergy could also be an underestimation, because several hundred dyes are handled in the dyehouses and we chose to test only the ones brought in by the patients.

Allergy to reactive dyes mediated by IgE seemed, in most cases, to develop within a year from the onset of exposure and asthma was often preceded by rhinitis. Pre-employment blood tests for total IgE or skin prick tests with common aeroallergens do not seem to be good predictors of the development of such an allergy.

In the persons with dermatitis, we found no positive patch test reactions to the reactive dyes. As many dyes are handled by each person every day, it could be difficult to identify the causative agent of a delayed allergic reaction and, therefore, we may not have tested the appropriate dyes. On the other hand, other chemical or physical factors may have caused the skin symptoms.

The RAST inhibition showed cross reactivity between some of the dyes. This implies that a person who had been sensitised by one dye may be at risk when exposed not only to the same dye but also to some other reactive dyes. The cross reactivity varied between patients, however, and thus seems to be dependent on individual immune response factors.

Reactive dyes have not been chemically defined. 
Remazol black B, for instance, consists of more than 10 components. $^{7}$ It is therefore difficult to identify the component (or components) responsible for the allergic reaction.

We have previously found that it was necessary to use a dye-protein conjugate in the RAST, and that directly dyed discs (discs without any carrier protein) resulted in poor and unreliable measures of specific IgE. ${ }^{12}$ This is not the case, however, for skin prick tests, where unconjugated dyes could be used successfully. This indicates that under conditions of excess rapid conjugation occurs in vivo at the test site.

Remazol black B, with colour index name reactive black 5, was suspected on the basis of anamnestic data to be a causative agent in several cases. Reactive black 5 is one of the most commonly used black dyes and is manufactured by many companies. Allergic asthma caused by this dye has been reported previously by Estlander $^{7}$ and by Docker et al. Feinstein and Djerassi have described two workers who firmly identified a black reactive dye (levafix black E5GA, colour index name reactive black 44 ) as responsible for provoking their symptoms of nocturnal asthma attacks ${ }^{8}$ and Park et al have described allergic asthma after exposure to a reactive dye called black GR. ${ }^{9}{ }^{10}$ We do not know if the identification of remazol black $B$ as a causative agent only reflects the fact that this dye is commonly used or if the dye has special chemical properties that make it active as a hapten.

Recently there have been reports that reactive dye specific IgG antibodies could be used as an indicator of exposure to reactive dyes although clinical symptoms seem to be related to increased serum concentrations of IgE but not IgG. ${ }^{1314}$

Although we do not fully understand the mechanisms involved, it seems clear that exposure to reactive dye powders should be considered a potential health hazard.
The study was supported by the Swedish Work Environment Fund Grant 84-1240.

1 Alanko K, Keskinen H, Björksten F, Ojanen S. Immediate-type hypersensitivity to reactive dyes. Clinical Allergy 1978;8 25-31.

2 Kalas D, Runstukova J. The effect of working with ostazine dyes on the development of bronchiospasm and occupational asthma. Pracovny Lekarstvi 1980;32:103-9.

3 Stern MA. Occupational asthma from a reactive dye. Ann Allergy 1985;55:264.

4 Hagmar L, Welinder $\mathrm{H}$, Dahlquist I. Immunoglobulin $\mathrm{E}$ antibodies against a reactive dye-a case report. Scand $J W$ ork Environ Health 1986;12:221-2.

5 Thoren K, Meding B, Nordlinder R, Belin L. Contact dermatitis and asthma from reactive dyes. Contact Dermatitis 1986; 15:186-93.

6 Docker A, Wattie JM, Topping MD, Luczynska CM, Newman Taylor AJ, Pickering CAC, Thomas P, Gompertz D. Clinical and immunological investigations of respiratory disease in workers using reactive dyes. $B r J$ Ind Med 1987;44:534-41.

7 Estlander T. Allergic dermatoses and respiratory diseases from ractive dyes. Contact Dermatitis 1988;18:290-7.

8 Feinstein O, Djerassi L. Occupational allergy to reactive dyes in a textile factory. In: Occupational health in the chemical industry. Copenhagen: World Health Organisation, 1989.

9 Park HS, Kim YJ, Lee MK, Hong C-S. Occupational Asthma and IgE antibodies to reactive dyes. Yonsei Med J 1989; 30:298-304.

10 Park HS, Lee MK, Hong C-S. Reactive dye induced occupational asthma without nonspecific bronchial hyperreactivity. Yonsei Med J 1990;31:98-102.

11 Luczynska CM, Topping MD. Specific IgE antibodies to reactive dye-albumin conjugates. J Immunol Methods 1986 95:177-86.

12 Wass $U$, Nilsson R, Nordlinder R, Belin L. An optimized assay of specific IgE antibodies to reactive dyes and studies of immunologic responses in exposed workers. $J$ Allergy Clin Immunol 1990;85:642-8.

13 Topping MD, Forster HW, Ide CW, Kennedy FM, Leach AM, Sorkin S. Respiratory allergy and specific immunoglobin $\mathrm{E}$ and immunoglobin $G$ antibodies to reactive dyes used in the wool industry. J Occup Med 1989;31:857-62.

14 Park HS, Kim JW, Hong CS. The prevalence of specific IgE and IgG to reactive dye-human serum albumin conjugate in workers of a dye factory and neighbouring factories. $J$ Korean Med Sci 1991;6:63-8.

Accepted 30 March 1992 